ISSN: 0514-7336 — ISSN electrónico: 2386-3943

DOI: https://doi.org/10.14201/zephyrus2021871531

\title{
LAS ESCENAS DE DANZA EN EL ARTE RUPESTRE LEVANTINO DEL BAJO ARAGÓN Y MAESTRAZGO: UNA SÍNTESIS CRÍTICA
}

\section{Dance Scenes in the Levantine Rock Art of Bajo Aragón and Maestrazgo: A Critical Synthesis}

\author{
Neemias Santos da Rosa*, Laura Fernández Macías* y Margarita Díaz-Andreu** \\ *Dpt. d'Història i Arqueologia. Facultat de Geografia i Història-Univ. de Barcelona. Carrer de Montalegre, 6. \\ 08001 Barcelona.Correo-e: neemias.sdarosa@gmail.com; laura.fernandez.macias@gmail.com.ID ORCID: https:// \\ orcid.org/0000-0001-8800-146X; https://orcid.org/0000-0001-7409-8993 \\ ** Univ. de Barcelona-Institució Catalana de Recerca i Estudis Avançats (ICREA). Pg. Lluis Companys, 23. 08010 \\ Barcelona. Correo-e: m.diaz-andreu@ub.edu. ID ORCID: https://orcid.org/0000-0003-1043-2336
}

Recepción: 21/01/2021; Revisión: 4/03/2021; Aceptación: 25/05/2021

Resumen: Desde el inicio de las investigaciones sobre el Arte Rupestre Levantino la bibliografía especializada ha reparado con cierta frecuencia en numerosas escenas calificadas como representaciones de danzas. Este artículo tiene como objetivo comprobar la plausibilidad de tales interpretaciones mediante el análisis del corpus de escenas identificadas como danzas en el Bajo Aragón y el Maestrazgo, dos regiones que juntas forman una misma provincia estilística. Empleando los conceptos teórico-metodológicos de la denominada Arqueología de la Danza, examinamos las imágenes de acuerdo con una serie de criterios analíticos orientados a la caracterización de los personajes de la acción y de las propias danzas representadas. Tras el análisis de estas, hemos concluido que solo cinco de las trece escenas publicadas como danzas presentan características que se ajustan a los parámetros de representación típicos de esta actividad. En ese sentido, identificamos una danza individual, dos en pareja y dos colectivas, las cuales parecen haber sido representadas de forma predominante en los últimos periodos cronoestilísticos de esta tradición rupestre.

Palabras clave: Mesolítico; Neolítico; Península Ibérica; España; Arqueología de la Danza; prácticas culturales; criterios analíticos.

AвSTRACT: From the beginning of the research on Levantine rock art a series of scenes have been considered as representations of dances. This article aims to check the likelihood of this identification as dances by analyzing the corpus of scenes regarded as such in the stylistic province of Bajo Aragón and Maestrazgo. Using the theoretical concepts and methodological approaches put forward by the Archaeology of Dance, we examine the scenes according to an explicitly defined set of criteria. These criteria refer to the individuals that participate in the dance and to the type of dance. As a result of our analysis, we conclude that only five out of the thirteen scenes published as dances present features that fit the parameters needed to represent this activity. Among the accepted scenes we identify one individual dance, two dances with couples and two collective dances. We argue that dance scenes seem to have been represented predominantly in the last chrono-stylistic periods of this rock art tradition.

Key words: Mesolithic; Neolithic; Iberian Peninsula; Spain; Archaeology of Dance; cultural practices; analytical criteria. 


\section{Introducción ${ }^{1}$}

De acuerdo con la antropóloga A. Kaeppler (1992: 196), la danza es una forma de comunicación no verbal creada a partir de símbolos culturalmente entendidos en contextos sociales y religiosos específicos, que combina los aspectos visuales, cinestésicos y estéticos del movimiento humano con la dimensión auditiva de los sonidos musicales. Con base en este concepto, estudios etnográficos indican que en sociedades preindustriales - tanto de cazadores-recolectores como de agricultores y pastores- la danza es predominantemente una herramienta para transmitir conocimientos y reglas culturales (Katz, 1982: 118; Bundo, 2001: 95-96), para mantener o reforzar la cohesión social (Marshall, 1969: $347-$ 349; Feld, 1982; Seeger, 2003: 698-699) y para explicar o acceder al mundo sobrenatural (Hanna, 1987: 203; Mguni, 2015: 52).

Desde el principio de la investigación sobre el arte levantino, hace ya más de cien años, se ha venido mencionando en la bibliografía la existencia de representaciones de danzas. La referencia más temprana se remonta a 1908, cuando el arqueólogo francés $H$. Breuil publica sus observaciones iniciales sobre las pinturas de la Roca dels Moros de Cogul (Lérida) en las que afirma que “... probablemente se trata de una danza de mujeres alrededor de un hombre..." (Breuil, 1908: 12), posteriormente describiendo el conjunto de forma más extensa en otro trabajo (Breuil y Cabré, 1909: 16). Durante las décadas siguientes, los comentarios sobre supuestas escenas de danza continuarán apareciendo en diversos escritos que serán posteriormente recogidos por F. Jordá en 1974 en una síntesis en la que se agrupan las representaciones en bailes fálicos, agrícolas, culto de deidades y ceremonias relacionadas con el matrimonio, la fertilidad, la guerra o eventos de tauromaquia.

1 Este trabajo se enmarca en el proyecto de la ERC Advanced Grant Artsoundscapes "The sound of special places: exploring rock art soundscapes and the sacred" (EC grant agreement 787842), cuya IP es M. Díaz-Andreu. Agradecemos a M. Bea y a A. Rubio habernos facilitado el acceso a buenas copias de varios calcos incluidos en este artículo.
Jordá ya apunta a contradicciones en las interpretaciones ofrecidas por varios autores y rechaza como danza la escena de la Cova de Rossegadors o El Polvorín, en Castellón, cuyas características describimos más adelante. Sin embargo, al no establecer parámetros claros sobre lo que hacía posible que una representación de baile pudiera considerarse como tal, en los años posteriores a este trabajo pionero la subjetividad seguirá jugando un papel importante en la interpretación de las pinturas. Así, es posible encontrar en la bibliografía que una misma imagen se haya interpretado de formas tan diversas como una danza, una recolección de alimentos, un acto de adoración o rendición, o un trabajo agrícola, como pasa, por ejemplo, en el caso del Barranco del Pajarejo (Almagro, 1960; Beltrán, 1968: 50; Jordá, 1974: 47; Mateo Saura, 1995-96: 83; García Benito, 2015: 349-350; Utrilla y Bea, 2016: 813-815)2.

En este artículo nuestro propósito es aplicar al arte levantino una serie de parámetros analíticos establecidos por Yosef Garfinkel, el creador de la llamada Arqueología de la Danza y el autor que más ha escrito sobre este tema en arqueología prehistórica. En base a estos parámetros, analizamos de una serie de representaciones interpretadas como danzas en la bibliografía de conjuntos rupestres del Bajo Aragón y del Maestrazgo (Fig. 1), dos zonas que, por las características paisajísticas de sus territorios y por la relativa homogeneidad tecnomorfológica de su arte rupestre, pueden ser consideradas como una provincia estilística (Utrilla y Bea, 2006).

\section{Consideraciones teórico-metodológicas}

Desde finales de la década de 1990 Y. Garfinkel ha ido publicando una serie de conocidos trabajos sobre la representación de danzas en cerámicas y arte rupestre de Europa y el Próximo Oriente. Nuestra

2 También García Benito, C.: Arqueología Musical Prehistórica: aproximación a través de la Arqueología Experimental aplicada a la Arqueo-Organología, de la Arqueoacústica y de la Iconografía Musical Prehistórica. Tesis doctoral inédita presentada en 2015 en la Univ. de Zaragoza. 


\begin{tabular}{|c|c|c|}
\hline \multicolumn{3}{|r|}{ CRITERIOS DE ANÁLISIS } \\
\hline GRUPO 1 & \multicolumn{2}{|r|}{ Personajes QUe Forman la escena } \\
\hline Criterio 1a & $\begin{array}{l}\text { postura corporal de los } \\
\text { danzantes }\end{array}$ & $\begin{array}{l}\text { dinámica, con brazos y/o piernas flexionadas, brazos levantados, troncos inclinados o } \\
\text { curvos }\end{array}$ \\
\hline Criterio $1 b$ & $\begin{array}{l}\text { objetos u ornamentos que } \\
\text { portan los danzantes }\end{array}$ & armamento, peinados, tocados, adornos corporales, etc. \\
\hline GRupo 2 & \multicolumn{2}{|r|}{ DANZA REPRESENTADA } \\
\hline Criterio $2 \mathrm{a}$ & $\begin{array}{l}\text { tipo de danza según el número } \\
\text { de individuos }\end{array}$ & individual, en pareja, colectiva lineal o colectiva circular \\
\hline Criterio $2 b$ & género de los bailarines & $\begin{array}{l}\text { en danzas colectivas los bailarines de un determinado grupo suelen ser del mismo } \\
\text { género, aunque en ciertos casos puede haber grupos mixtos }\end{array}$ \\
\hline \multirow{2}{*}{ Criterio $2 c$} & \multirow{2}{*}{$\begin{array}{l}\text { clase de interacción entre los } \\
\text { danzantes }\end{array}$} & $\begin{array}{l}\text { bailarines representados generalmente uno cerca del otro, manteniendo contacto físico } \\
\text { con los demás personajes o sin tocarlos }\end{array}$ \\
\hline & & $\begin{array}{l}\text { los individuos involucrados en la acción han de exhibir posturas corporales similares que } \\
\text { indican la realización de un mismo tipo de movimiento }\end{array}$ \\
\hline \multirow[b]{2}{*}{ Criterio $2 \mathrm{~d}$} & \multirow[b]{2}{*}{$\begin{array}{l}\text { dirección del movimiento de } \\
\text { la danza }\end{array}$} & en danzas con dos o más personajes la dirección de los movimientos suele ser uniforme \\
\hline & & $\begin{array}{l}\text { los personajes bailan en un mismo punto -realizando movimientos verticales- o realizan } \\
\text { desplazamientos horizontales en el espacio, con movimientos orientados hacia la derecha } \\
\text { o hacia la izquierda -en sentido horario o antihorario en bailes circulares- }\end{array}$ \\
\hline
\end{tabular}

Fig. 1. Definición y explicación de los criterios empleados para considerar una escena como danza, en base a los parámetros de análisis establecidos por Garfinkel (2003: 27-102).

metodología se basa, pues, en la de este autor, ajustada a la especificidad del arte levantino. Siguiendo a Garfinkel, distinguimos dos grupos de criterios analíticos: uno concerniente a los personajes que forman la escena (Fig. 1, Grupo 1) y otro que compete a la posible danza representada (Fig. 1, Grupo 2). En el primer grupo destacan tanto el dinamismo que refleja la postura corporal de los danzantes como los objetos u ornamentos que portan. En lo que se refiere a la postura corporal, los individuos que ejecutan bailes generalmente muestran brazos y/o piernas flexionados, brazos levantados, troncos inclinados o curvos, etc. (Garfinkel, 2003: 19), y es este dinamismo el que permite que incluso antropomorfos aislados que presentan estas características puedan asociarse a un posible baile. Por otra parte, en cuanto a los objetos o elementos de ornamentación -como peinados, tocados, máscaras o adornos corporales- constituyen la parafernalia que los ejemplos etnográficos suelen mostrar asociada a esta actividad cultural (Garfinkel, 2003: 34-41; 2010: 206).

El segundo grupo de criterios analíticos se refiere a la danza en sí. En este distinguimos el tipo de baile según el número de individuos, el género de los personajes, la clase de interacción entre los mismos y la dirección de los movimientos. En cuanto al tipo de baile, Garfinkel asume en sus publicaciones que la danza implica a varios bailarines cuando afirma que debe estar representada por más de una figura para que la escena pueda considerarse completa (Garfinkel, 2010: 207). Sin embargo, en este aspecto seguimos a los especialistas del arte levantino en nuestra perspectiva de que también puede haber individuos aislados realizando esta actividad, una visión corroborada por la existencia de estos bailarines solitarios en otras áreas del mundo (Lewis-Williams, 1999; Lewis-Williams y Challis, 2011; Whitley, 2011; Winkelman, 2017). Además de los danzantes aislados distinguimos, como hace Garfinkel, los bailes en pareja y los bailes colectivos -con tres o más participantes, que pueden estar organizados de forma lineal o circular-. La siguiente categoría, la de género, es más informativa que definitoria, en el sentido de que a través de la información que nos comunica intentamos discernir si fueron hombres o mujeres los que se implicaron en danzas, o si hubo danzas mixtas.

Los dos últimos puntos a considerar son la interacción entre los personajes y la dirección de los movimientos. En relación al primero, en los bailes con dos o más participantes, estos suelen ser representados uno cerca del otro, manteniendo contacto 
físico con los demás personajes o sin tocarlos (Garfinkel, 2003: 24). En cualquiera de estos escenarios los personajes han de mostrar algún grado de sincronía o, lo que es lo mismo, han de exhibir posturas corporales similares que indican la realización de un mismo tipo de movimiento (Garfinkel, 1998: 222; 2003: 60; 2010: 209). Tal sincronismo es de fundamental importancia porque, como demuestran estudios recientes de neurociencia, las actividades rituales basadas en la ejecución de movimientos sincronizados -como la danza- producen en los participantes profundos sentimientos de unidad grupal, llevando a la consolidación de valores sociales y sagrados entre los miembros de la comunidad y facilitando el desarrollo de comportamientos cooperativos (Rossano, 2020: 25-26).

Sobre la dirección del movimiento, Garfinkel menciona que es importante observar la posición del cuerpo de los personajes, que indica si el baile reproducido se desarrolla con movimientos orientados hacia la derecha o hacia la izquierda (en el sentido de las agujas del reloj o a la inversa, en el caso de las danzas circulares), o si se realiza con los individuos bailando en un mismo punto, es decir, sin desplazamiento horizontal en el espacio. En escenas con dos o más participantes, estos suelen representarse ejecutando movimientos que siguen una dirección uniforme lo que, unido al mantenimiento de un espacio constante entre las figuras, contribuye a generar un efecto visual de movimiento rítmico (Garfinkel, 1998: 210; 2003: 19).

\section{Análisis de las escenas}

En este apartado analizaremos las trece escenas identificadas en once abrigos de arte rupestre del área de estudio (Fig. 2) en las que diversos autores han creído observar danzas, dividiendo las mismas en tres grandes grupos según el número de personajes incluidos en la acción: escenas con un personaje, escenas con dos personajes y escenas con tres o más personajes. A su vez, en cada uno de estos grupos, describiremos las imágenes ordenando nuestra exposición según el nombre de los sitios, e identificaremos aquellas que, de acuerdo con la metodología empleada en nuestra investigación, presentan los atributos necesarios para su clasificación como un baile, las que no permiten establecer una conclusión definitiva y las que claramente no se ajustan a los criterios típicos de representaciones de danza. Una síntesis de nuestros resultados se ofrecerá en la discusión.

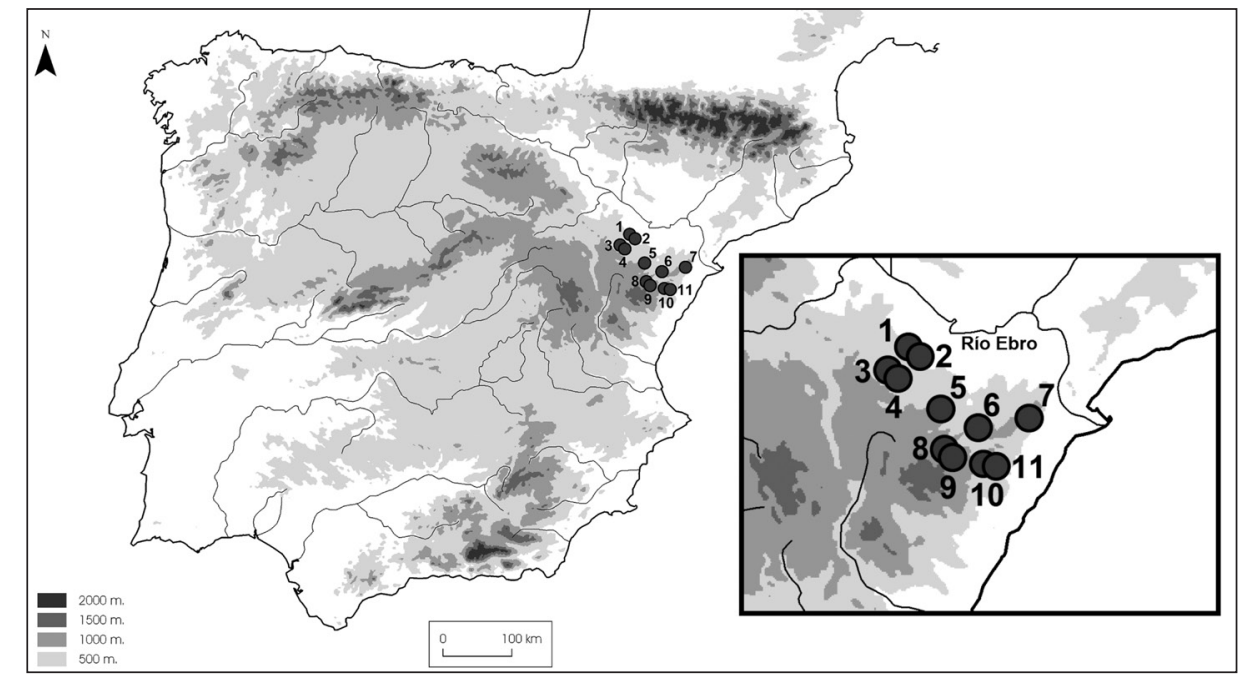

Fig. 2. Localización geográfica de los conjuntos de arte levantino del Bajo Aragón y del Maestrazgo mencionados en el texto: 1) Abrigo de los Trepadores (Alacón, Teruel); 2) Abrigo del Tío Garroso (Alacón, Teruel); 3) Abrigo de la Cañada de Marco (Alcaine, Teruel); 4) Cueva del Chopo (Obón, Teruel); 5) Abrigo de la Vacada (Castellote, Teruel); 6) Galería del Roure (Morella, Castellón); 7) Cova de Rossegadors o El Polvorín (La Pobla de Benifassà, Castellón); 8) Cova Remígia (Ares del Maestrat, Castellón); 9) Cingle de la Mola Remígia (Ares del Maestrat, Castellón); 10) Cova del Civil (Tírig, Castellón); 11) Cova de la Saltadora (Les Coves de Vinromà, Castellón). 


\subsection{Escenas con un solo personaje}

\subsubsection{Abrigo de la Cańada de Marco (Alcaine, Teruel) (Fig. 3a)}

En este conjunto rupestre, en su Zona 4, se encuentra un antropomorfo de género indeterminado interpretado como un posible danzante. Este personaje exhibe una cabeza bien delineada y orientada hacia la izquierda, un tronco muy curvo y brazos levantados, ostentando lo que parece ser un haz de flechas. Por otro lado, sus piernas no son visibles, ya que las líneas presentes en la parte inferior del cuerpo corresponden a los restos de otra figura incompleta (Ruiz y Royo, 2017: 70). Según A. Beltrán (1998: 49), este personaje estaría bailando y se encontraría directamente relacionado con otro motivo situado a su derecha, correspondiente a una supuesta mujer sentada, formando así una escena de danza frente a una figura entronizada.
Analizando la imagen es posible observar que el individuo parece estar en movimiento. Aunque el uso de adornos corporales u otra ornamentación no son evidentes, está claro que el antropomorfo porta un objeto. Sin embargo, la imposibilidad de visualizar sus piernas impide determinar con seguridad la postura corporal, lo que nos lleva a considerar demasiado arriesgado establecer una conclusión definitiva. En este sentido, la asociación entre este personaje y la figura sentada debe ser tomada con cautela, ya que de acuerdo con Ruiz y Royo (2017) no todos los motivos del panel serían contemporáneos.

\subsubsection{Abrigo del Tío Garroso (Alacón, Teruel)} (Fig. 3b)

En el Panel I de este abrigo se encuentra un arquero de características morfológicas muy estilizadas

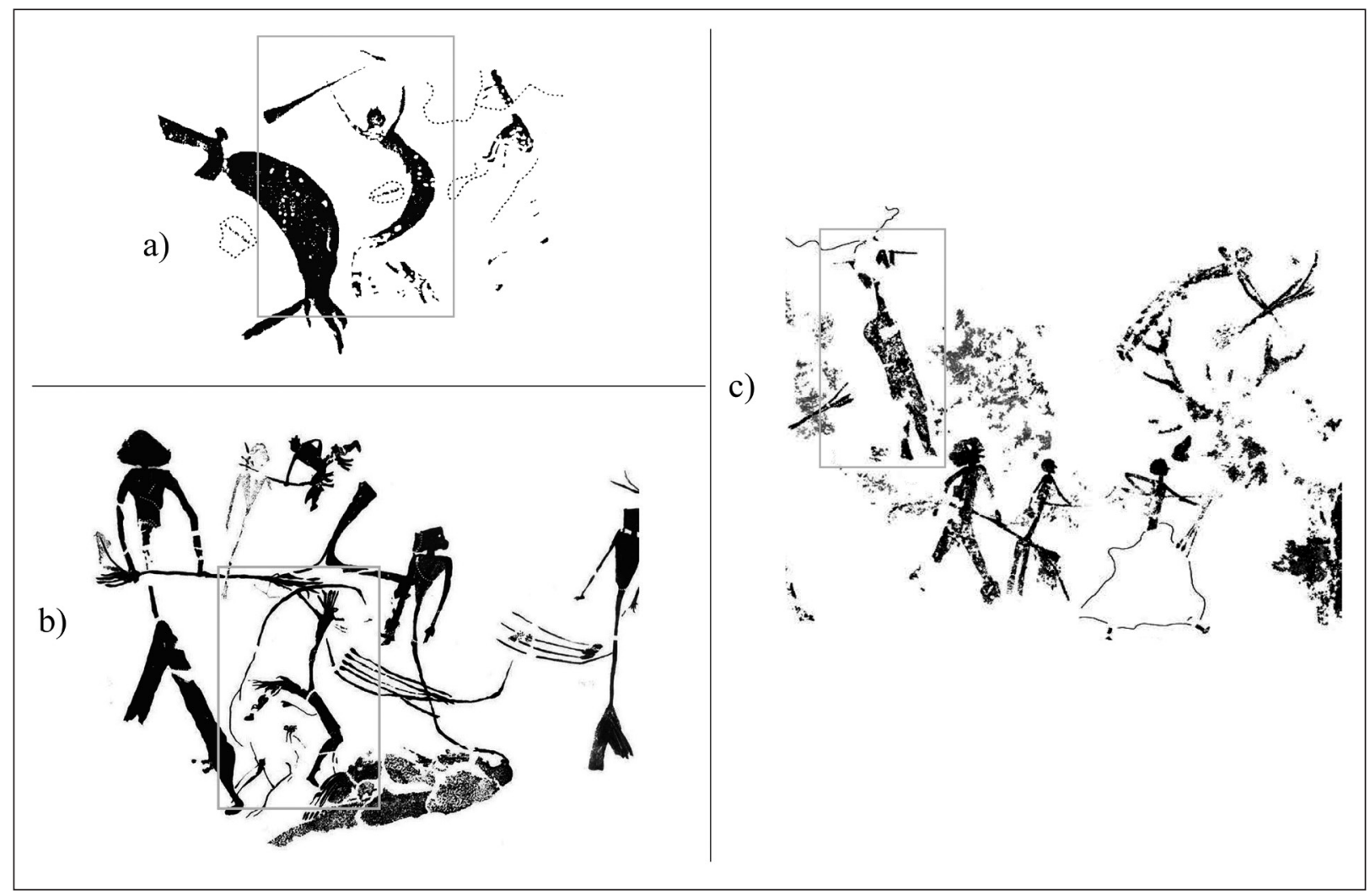

Fig. 3. a) Abrigo de la Cañada de Marco (Beltrán, 1998: 50, fig. 7); b) Abrigo del Tío Garroso (Beltrán y Royo, 2005: ficha 007); c) Cova de Rossegadors o El Polvorín (La Pobla de Benifassà, Castellón) (Viñas et al., 2015: 142, fig. 138). 
que, según varios autores, parece estar realizando algún tipo de danza (Beltrán y Royo, 2005; Jordán, 2006: 86; Bea, 2018: 258). Dispuesta en perspectiva frontal, esta figura presenta la cabeza adornada con un posible tocado de plumas y exhibe el tronco ligeramente curvado, lo que intensifica la sensación de movimiento. Uno de los brazos se muestra elevado y sostiene un arco, y la porción visible del otro permite suponer la misma posición. Sus piernas aparecen bastante abiertas y parcialmente flexionadas, estando una de ellas elevada presentando un adorno en la rodilla, a la vez que la otra se mantiene como base en contacto con el suelo. Analizando el contexto del panel es posible observar que este individuo no dispara el arco ni parece estar involucrado en ninguna acción de carácter cinegético. Así, su postura corporal dinámica asociada con el uso de objetos y ornamentación permite considerar que podría estar bailando. En este caso, el tipo de movimiento realizado con los brazos y piernas indica que el personaje estaría danzando sin realizar desplazamientos horizontales en el espacio.

\subsubsection{Cova de Rossegadors o El Polvorín (La Pobla de Benifassà, Castellón) (Fig. 3c)}

En la parte superior del Panel v de este sitio se identifica una representación femenina interpretada por algunos autores como una divinidad de la caza (Jordá, 1974) y por otros como una bailarina (Vilaseca, 1947; Beltrán, 1968: 22). Según la descripción de R. Viñas et al. (2015: 139) el motivo presenta un cuerpo estilizado con un tronco delgado, brazos flexionados hacia arriba, glúteos prominentes, piernas rectas y largas, con pantorrillas y pies bien definidos. Los procesos de degradación que afectan el soporte han eliminado la cabeza y uno de sus hombros, pero aun así es posible observar que la mujer llevaría una especie de vara en cada mano, o tal vez un bastón -ahora incompleto-, que se cruzaría entre el cuello y la espalda. Su orientación indica que estaría mirando hacia la derecha, quizás acompañando a un grupo de arqueros involucrados en una acción que se está llevando a cabo en su entorno. En ese sentido, el escaso movimiento en las extremidades inferiores de la figura dificulta su clasificación definitiva como una bailarina. A pesar de que la posición dinámica de sus brazos y de que el objeto -o los objetos- que tiene en sus manos podrían formar parte de una coreografía, no nos parece posible clasificar de manera definitiva esta fémina como una danzante.

\subsection{Escenas con dos personajes}

\subsubsection{Abrigo de la Vacada (Castellote, Teruel)}

(Fig. 4a)

Entre las escasas composiciones que muestra este abrigo se encuentra una escena protagonizada por dos arqueros, hoy incompletos, dispuestos uno frente al otro, interpretada por Ripoll (1961) como la representación de una danza de carácter bélico. Según Bea (2006-08: 130-131), la parte superior del cuerpo de estos dos personajes -la única preservada- indica la adopción de una postura esencialmente estática, con los brazos rectos para sostener el arco o flexionados para sostener una sola flecha. En el individuo de la derecha se advierte un adorno en forma de cola de caballo en la cintura y la presencia de una larga melena terminada en siete pequeñas trenzas. En el motivo frente a él también se observa una gran melena, existiendo ciertas dudas sobre el uso del adorno antes mencionado y sobre una posible honda colocada en su hombro izquierdo. En este contexto, Bea (2006-2008: 131) señala que la interpretación de Ripoll se basó en la existencia de una supuesta curvatura pronunciada en el tronco del arquero posicionado a la derecha, una curvatura que en realidad es una ilusión óptica causada por la pérdida de parte de la pintura y la morfología del adorno utilizado por el personaje. Sumada a este hecho la ausencia de un dinamismo claro o cualquier otra indicación de movimientos rítmicos, descartamos la clasificación de esta escena como una representación de danza. 


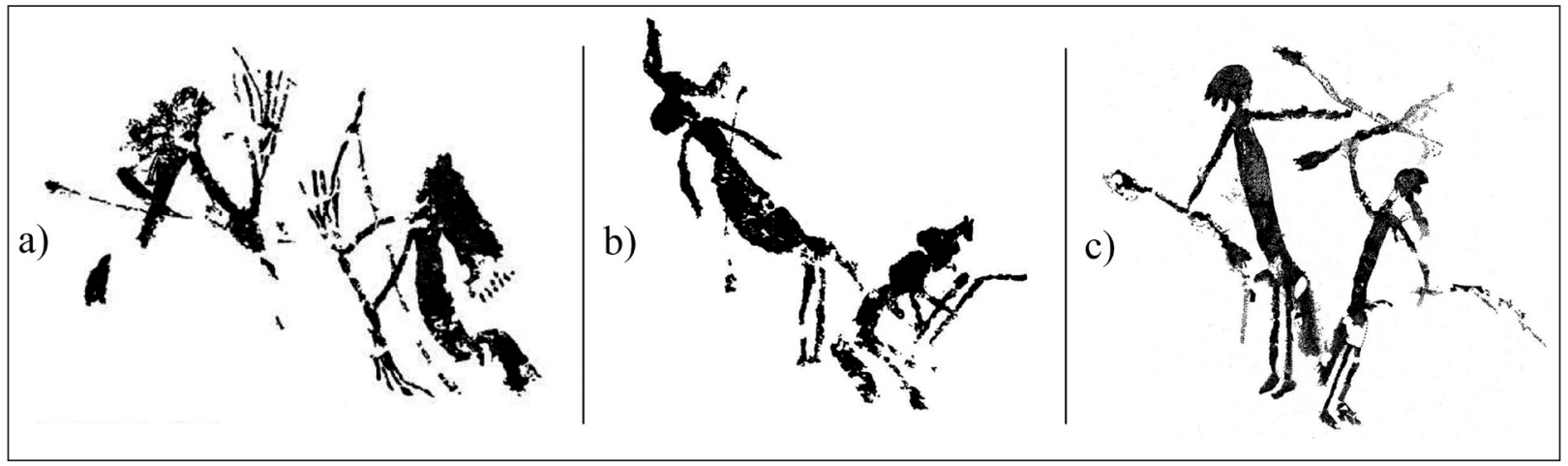

Fig. 4. a) Abrigo de la Vacada (Bea, 2006-2008: 130, fig. 2); b) Cingle de la Mola Remigia (López-Montalvo, 2018: 216, fig. 11); c) Cova Remígia (Viñas y Martinez, 2001: 375, fig. 5).

3.2.2. Cingle de la Mola Remígia (Ares del Maestrat, Castellón) (Fig. 4b)

Entre los motivos más singulares de este conjunto rupestre se encuentran dos pequeñas figuras con características antropozoomorfas identificadas en el Abrigo v. De acuerdo con la descripción de R. Viñas y R. Martínez (2001: 374), el primero de estos personajes se encuentra orientado hacia la izquierda, es de mayor tamańo y presenta una gran cabeza de toro, lo que parece indicar el uso de algún tipo de máscara. Su tronco, con la región abdominal abultada, aparece inclinado hacia adelante, y sobre él se observa un arco. Sus brazos permanecen paralelos al cuerpo y sus piernas se muestran juntas, con una ligera flexión en una rodilla, mientras que en la región posterior de la cadera se puede observar la presencia de un adorno en forma de cola larga. El segundo individuo, orientado hacia la derecha, exhibe rasgos faciales y un tocado con morfología similar a la de la cabeza de un cervatillo. Su tronco se proyecta hacia adelante y en sus manos sostiene objetos interpretados como un arco y una flecha. Por otro lado, sus piernas se muestran rectas y en ángulo diagonal al eje vertical, sin indicación de desplazamiento. En la parte inferior de su espalda se observa un adorno similar a la cola de un lobo o zorro.

E. Ripoll (1963) interpretó esta escena como un baile y, poco después, Jordá $(1970-71$; 1974) clasificó la composición como una danza ritual agrícola, basada en la representación de un dios-toro, y como un culto relacionado con la fertilidad, cuyas raíces se encontrarían en las creencias del Oriente Próximo. Por nuestra parte, analizando los atributos identificados en las figuras y teniendo en cuenta los convencionalismos típicos del arte levantino, nos inclinamos por clasificar la imagen como una posible escena de baile protagonizada por dos individuos del género masculino -no femenino, como opinan Escoriza (2002: 90-91) y Olaria (2011: 153)-. La postura corporal de estos personajes es claramente dinámica, ya que esta proyección frontal del tronco no es anatómicamente natural y solo se puede obtener realizando movimientos. Además, los diversos elementos de ornamentación y el uso de objetos fuera de su función original -arcos y flechas que no son utilizados para cazar- se ajustan adecuadamente al tipo de parafernalia generalmente asociada con la danza. A pesar de estar orientados en direcciones opuestas, ambos antropomorfos parecen realizar un movimiento rítmico sincronizado y ejecutado en el mismo lugar, basado en la inclinación frontal del tronco. Como se puede observar, la interacción entre las figuras es muy estrecha, hasta el punto de generar una superposición entre ellas. Por otro lado, el contexto del panel indica que no están directamente asociados con ningún otro motivo relacionado con actividades cotidianas, lo que de alguna manera parece reforzar su carácter simbólico y ceremonial. 


\subsubsection{Cova Remígia (Ares del Maestrat, Castellón) (Fig. 4c)}

En medio del amplio repertorio de imágenes de este abrigo, es de especial interés la representación de dos pequeñas figuras masculinas con características particulares, interpretadas como protagonistas de una danza fálica (Jordá, 1974: 46). Orientadas en direcciones opuestas, ambas tienen rasgos faciales muy pronunciados, interpretados como disfraces de pájaros (Jordá, 1974: 46). Con el tronco inclinado hacia adelante, muestran un brazo bajado y el otro levantado, exhibiendo objetos que parecen corresponderse con arcos y flechas, mientras que sus piernas se muestran rectas y sin indicaciones de desplazamiento. A la altura de las caderas es posible notar la indicación de sus falos erectos y de adornos en forma de cola gruesa. Finalmente, la interacción entre los antropomorfos es cercana al punto de haber superposición entre los objetos que ostentan en sus manos.

Analizando este conjunto de características, encontramos los atributos necesarios para considerar la escena como una posible representación de danza en pareja. En este sentido, el evidente dinamismo presente en la postura corporal de los individuos parece indicar la realización de movimientos rítmicos basados en la inclinación del cuerpo hacia adelante y el movimiento alternado de los brazos, sin el desplazamiento horizontal de los personajes en el espacio. Además, la exhibición de adornos corporales y quizás de máscaras, así como el uso de objetos ajenos a su función original, son aspectos típicos de bailes rituales, lo que corroboraría esta clasificación.

\subsection{Escenas con tres o más personajes}

\subsubsection{Abrigo de los Trepadores (Alacón, Teruel) (Fig. 5a)}

En este abrigo se encuentra una escena formada por siete antropomorfos posicionados uno al lado del otro y con una misma postura corporal. Estos personajes exhiben un tronco triangular que en algunos casos aparece inclinado, las piernas abiertas y los brazos levantados, ostentando posibles arcos (Molinos, 1986-1987: 305). Representados en un plano diagonal y con suficiente proximidad para que haya superposición entre sus brazos y piernas, se hace evidente la interacción de los siete individuos en una misma acción, en la cual se percibe la realización de un mismo movimiento de forma simultánea. En este sentido, la rigidez de sus piernas parece indicar que no se desplazan en el espacio, sino que mueven sus cuerpos de manera rítmica mientras permanecen en el mismo lugar. Ante estos arqueros se encuentra una figura tradicionalmente interpretada como un individuo muerto (Ortego, 1948: 14), razón por la cual M. I. Molinos (198687: 305) clasificó esta escena como una ejecución, celebración o baile ritual. De hecho, el dinamismo de los personajes, su estrecha interacción, la asociación con objetos empleados de forma ajena a su función original y la clara realización de un movimiento sincronizado son suficientes para considerar plausible la clasificación de esta escena como una danza colectiva lineal, tal vez realizada en un contexto bélico.

\subsubsection{Cova de la Saltadora (Les Coves de Vinromà, Castellón) (Fig. 5b)}

En el Abrigo Ix de este sitio se observa una escena formada por tres motivos masculinos -femeninos según Ripoll (1961)- cuya interpretación genera divergencias. Relativamente separados de otras figuras en el panel, los tres personajes están orientados hacia la izquierda. Al menos dos de ellos parecen mostrar tocados con forma de antenas y todos exhiben el tronco inclinado hacia adelante. Sus piernas robustas y bien delineadas están incompletas en los dos primeros, mientras que en el tercero faltan los pies. La disposición de sus brazos es un elemento clave para la interpretación de la escena. Según I. Domingo et al. (2007: 154-159), el primer antropomorfo muestra los brazos flexionados detrás del cuello, y debajo de estos, a cada lado del tronco, aparecen líneas verticales. Los brazos de las otras figuras se ven comprometidos por el mal estado de conservación de la imagen. Sin embargo, parecen 


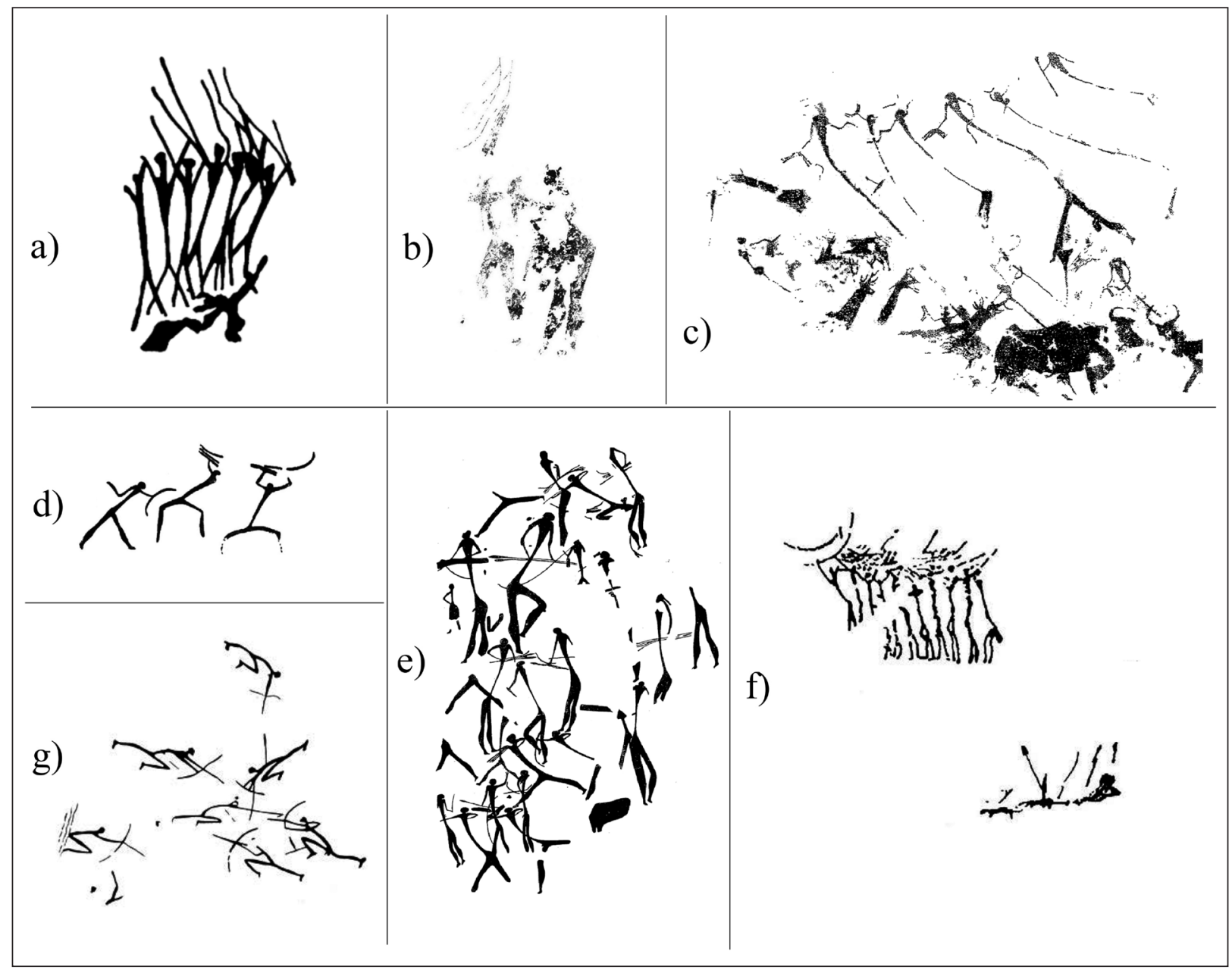

Fig. 5. a) Abrigo de los Trepadores (Ortego, 1948: 3); b) Cova de la Saltadora (Domingo et al., 2007: 156, fig. 40); c) Cueva del Chopo (Picazo y Bea, 2005: 285, fig. 1); d) Cova del Civil (López-Montalvo, 2007: 153, fig. 7.19); e) Cova del Civil (Obermaier y Wernert, 1919: 31, fig. 15); f) Cova Remígia (Porcar, 1945b: 150, fig. 8); g) Galería del Roure (Hernández Pacheco, 1917: 73, fig. 7).

estar flexionados con los antebrazos proyectados hacia adelante, de modo que uno de los brazos del tercer personaje parece tocar la espalda del segundo. También cabe señalar los dos arcos y un conjunto de flechas situados a pocos centímetros sobre la cabeza del primer individuo.

De acuerdo con algunas interpretaciones esta sería una escena de danza (Almagro, 1946; Beltrán, 1985: 119), mientras que otros investigadores consideran que la imagen podría ilustrar el apresamiento de un individuo (Domingo et al., 2007; Bea, 2020).
Analizando la representación es posible observar que los tres personajes se encuentran involucrados en la misma acción, siendo evidente la adopción de una misma postura corporal por parte del segundo y el tercero, que muestran sus brazos flexionados y el tronco proyectado hacia adelante. Sin embargo, la posición del cuerpo del primer antropomorfo dificulta la interpretación de la escena, de modo que, como señalan Domingo y otros (2007: 158), las líneas que cuelgan al lado de su tronco podrían corresponder a algún tipo de cuerda que, sostenida 
por la segunda figura, mantendría sus manos atadas detrás de su cabeza, dando a la composición un carácter violento. Por otro lado, las mencionadas líneas también podrían ser adornos que, asociados con la posición distintiva de los brazos y la postura ligeramente más vertical del torso, podrían estar dando al primer personaje una función de líder de una danza lineal. En cualquier caso, el mal estado de conservación de las figuras no permite el establecimiento de una conclusión definitiva.

\subsubsection{Cueva del Chopo (Obón, Teruel) (Fig. 5c)}

En este abrigo se encuentra una gran escena formada por catorce figuras humanas. De acuerdo con Picazo et al. (2001-2002: 38-39), a la izquierda del panel se observa la presencia de dos antropomorfos incompletos orientados hacia la derecha, los cuales tienen un tronco de morfología triangular que asume una forma lineal y desproporcionadamente alargada que se extiende hasta la cadera. Sus brazos están flexionados y proyectados hacia arriba o hacia adelante, exhibiendo bumeranes y otros instrumentos difíciles de identificar, mientras que sus piernas, solo parcialmente visibles en el segundo motivo, aparecen abiertas. Por otro lado, a la derecha del panel se observa una gran agrupación de figuras organizada en dos filas de individuos orientados hacia la izquierda. La fila superior está formada por seis personajes con dimensiones que alcanzan más de $1 \mathrm{~m}$ de longitud, mientras que la inferior está compuesta por otros seis más pequeños. Morfológicamente, todos muestran características similares, presentando cabezas redondeadas y ligeramente aplanadas, adornadas con tocados de plumas en al menos dos ocasiones. El tronco, desproporcionado y siempre inclinado hacia adelante, exhibe una forma triangular en la parte superior y, desde este punto, se convierte en una línea curva y larga que baja hasta la cadera. Sus brazos aparecen flexionados y proyectados hacia arriba y/o hacia adelante, con un solo caso en el que se mantienen rectos. En sus manos llevan uno o más bumeranes, mientras que el último individuo de la escena exhibe un bastón. En los casos en que es posible observar las extremidades inferiores, sus piernas aparecen abiertas y en posición de marcha, o bien cerradas y juntas para indicar que el personaje no se desplaza.

Según M. Bea (2018: 293), esta escena podría mostrar una confrontación bélica, un desfile o un baile ritual. Sin embargo, algunos aspectos de la imagen impiden su clasificación como una danza colectiva. A pesar del dinamismo de las representaciones y la clara interacción entre ellas, la variabilidad en la posición de los brazos y las piernas -que muestran la existencia de individuos en movimiento y de otros parados en el mismo lugar- deja en claro que los personajes no realizarían movimientos rítmicos sincrónicos. Por lo tanto, aunque el mal estado de conservación de las figuras no permite hacer afirmaciones categóricas, las propuestas relacionadas con una posible confrontación bélica parecen ser las más coherentes con las características de la escena.

\subsubsection{Cova del Civil (Tírig, Castellón) (Fig. 5d-e)}

En este abrigo se identifica la presencia de dos escenas descritas en la bibliografía como representaciones de danzas. La primera está formada por tres pequeños arqueros incompletos, dispuestos en perspectiva frontal $\mathrm{u}$ orientados hacia la derecha, con cabezas redondeadas y el tronco inclinado. En el primer personaje, un brazo aparece flexionado y proyectado hacia atrás, mientras que el otro sostiene un arco frente al cuerpo; las piernas, a su vez, se muestran abiertas y en actitud de desplazamiento. Los otros dos individuos adoptan una postura corporal distinta, con las piernas abiertas y flexionadas, mientras que sus brazos, parcialmente incompletos, están levantados, sosteniendo lo que parecen ser arcos y flechas.

Para H. Obermaier y P. Wernert (1919: 129), y también para R. Viñas (1982: 118), estos arqueros podrían estar bailando, mientras que para $\mathrm{E}$. López-Montalvo (2007: 154) podrían estar cruzando por un área de vegetación o por la corriente de un río. En este contexto, la realización de una danza colectiva de tipo lineal protagonizada por los tres personajes parece, en un primer análisis, poco 
probable debido a la postura de la marcha adoptada por la primera figura, que contrasta con los movimientos aparentemente coordinados de los otros arqueros. Sin embargo, no se puede excluir la posibilidad de que el primer antropomorfo participara en la acción liderando el progreso de un baile realizado por los demás individuos; del mismo modo, no podemos obviar la posibilidad de que la composición represente alguna de las hipótesis sugeridas por López-Montalvo (2007).

En la segunda escena se observa la presencia de veintiséis motivos de arqueros y de al menos una figura femenina, personajes que, para algunos autores, estarían realizando una danza de carácter mágico para atraer el éxito en las batallas (Obermaier y Wernert, 1919: 129; Porcar, 1945b: 32). Los arqueros presentan cuerpos estilizados que llegan a superar los $30 \mathrm{~cm}$ de longitud, con cabezas redondeadas en las que a veces es posible observar tocados de plumas realizados con pintura blanca. Sus troncos aparecen generalmente inclinados, con una morfología triangular en la parte superior que luego asume una forma lineal que se extiende hasta la cadera. Los brazos aparecen rectos o flexionados y proyectados hacia adelante o hacia abajo, portando arcos, flechas e incluso lo que parece ser un carcaj, o disparando su armamento. Las piernas se muestran abiertas, juntas o con una rodilla doblada, siendo posible observar los pies. De los veinticuatro casos en los que es posible identificar la orientación de la figura, veintiún personajes aparecen orientados hacia la izquierda, dirigidos a la parte del panel donde otros arqueros protagonizan una escena bélica (Cabré, 1925: 206; Molinos, 1986-1987: 301), mientras que solo tres se encuentran orientados hacia la derecha.

De acuerdo con Jordá (1974: 49-50) el supuesto baile estaría formado por arqueros dispuestos cara a cara y organizados en parejas con actitudes similares, estructurando una composición presidida por una deidad femenina. Sin embargo, al examinar esta escena y el contexto del panel, no encontramos elementos que permitan clasificarla como una danza colectiva. Aunque la mayoría de los personajes aparecen en posiciones esencialmente dinámicas, la gran variabilidad de las posturas corporales adoptadas por ellos se hace evidente, indicando que no hay coordinación entre sus movimientos. Además, un análisis detallado del posicionamiento de los individuos no respalda la idea de que se encuentran organizados en parejas o en actitudes paralelas. Del mismo modo, el predominio de una orientación hacia la izquierda indica que estos arqueros no forman una composición aislada, sino que probablemente son parte de la escena bélica que se extiende hasta la parte opuesta del panel.

\subsubsection{Cova Remígia (Ares del Maestrat, Castellón) (Fig. 5f)}

En el Abrigo v de este conjunto rupestre se encuentra una imagen con características muy similares a la del Abrigo de los Trepadores. En este caso, la escena está formada por diez arqueros de aspecto linear, pintados uno al lado del otro y situados a escasos centímetros de una figura humana flechada y aparentemente muerta. Estos individuos exhiben cabezas con morfología redondeada, un tronco vertical o ligeramente inclinado, brazos levantados ostentando arcos y piernas en posición estática. En el último personaje situado a la derecha se observa la presencia de un adorno en forma de cola gruesa a la altura de la cadera, un elemento que es visible también en la pareja de bailarines con características antropozoomorfas representadas en este mismo abrigo -cf. apartado 3.2.3. supra-.

En base a estas características, J. B. Porcar (1945a: 150) interpretó la composición como una danza de arqueros frente a una figura humana sacrificada. De hecho, está claro que los diez individuos interactúan de manera estrecha en la misma acción, expresando dinamismo en la parte superior de sus cuerpos a través de un movimiento coordinado de los brazos. Además, la elevación sincronizada de los arcos, el uso de un adorno -actualmente visible en al menos un personaje- y la presencia de una figura supuestamente sacrificada delante del grupo de arqueros confieren a la escena un carácter fuertemente simbólico, lo que contribuye a su clasificación como una posible danza colectiva de tipo lineal, tal vez 
asociada a un acto de celebración de carácter violento. En este sentido, vale la pena señalar que en este mismo abrigo se encuentran otras tres representaciones de estructura similar, interpretadas por E. Sarrià (1988-1989: 18) como imágenes de ejecuciones o sacrificios, pero que quizás podrían corresponder también a escenas de danza (Porcar, 1945a: 150-151). Sin embargo, su estado de conservación no permite llevar a cabo un análisis más detallado de las mismas.

\subsubsection{Galería del Roure (Morella, Castellón) (Fig. 5g)}

Los siete arqueros que componen la escena en cuestión tienen características morfológicas prácticamente idénticas y fueron pintados con un alto grado de dinamismo. Cuatro están orientados hacia la derecha y tres hacia la izquierda; todos presentan una cabeza redondeada y un tronco delgado proyectado hacia adelante. Sus brazos se representan con líneas rectas que a veces dan lugar a las flechas mismas que disparan, aunque al menos en una ocasión se ha indicado el movimiento de flexión del codo para causar tensión en el arco. Con respecto a las extremidades inferiores, mientras que una pierna se muestra adelantada y con la rodilla flexionada, la otra permanece estirada, con una disposición de los pies que refuerza la sensación de movimiento. Cabe destacar la presencia de líneas rectas en la espalda de uno de los arqueros y, en la pierna de otro, líneas que parecen corresponder a flechas disparadas por sus adversarios.

Las interpretaciones de esta escena varían entre el retrato de un acontecimiento bélico (Hernández Pacheco, 1917: 71-74; Molinos, 1986-87: 299; Mateo, 1995-96: 85; Rubio et al., 2019: 230) y la representación de un baile guerrero (Jordá, 1974: 50; Ripoll, 1990: 74; Alonso y Grimal, 2001: 134; Mesado et al., 2008: 188). En este sentido, a pesar del claro dinamismo de sus personajes, no encontramos en esta composición la 'gran regularidad' en la disposición de los arqueros o el “... acompasado movimiento de una danza llevada a cabo por tres parejas..." descrito por ciertos autores (Jordá,
1974: 50). Por el contrario, observamos que incluso los arqueros orientados en la misma dirección siguen diferentes líneas de desplazamiento, de modo que los siete individuos no aparecen organizados espacialmente de una manera específica. Además, las posibles flechas clavadas en dos de los mismos contribuyen a la interpretación de la composición como un evento bélico y a la refutación de las hipótesis relacionadas con un baile.

\section{Discusión}

Tras analizar las trece escenas mencionadas en la bibliografía como imágenes de danzas, encontramos que solo cinco de estas exhiben las características típicas de representaciones de esta actividad. De este modo, identificamos una danza individual en el Abrigo del Tío Garroso dos en pareja en el Cingle de la Mola Remígia y en Cova Remígia, y dos bailes colectivos de tipo lineal, ubicados en el Abrigo de los Trepadores y en Cova Remígia (Fig. 6). En ese contexto, si desde un punto de vista cuantitativo llama la atención la baja proporción de estas escenas en el corpus temático de arte levantino del área de estudio, eso no significa necesariamente que tal actividad tuviera una importancia menor en las comunidades que produjeron las imágenes. Como ejemplifica Garfinkel (1998) aludiendo al pueblo San o bosquimano de África meridional, aunque las danzas colectivas juegan un papel crucial en su cosmología, por razones no explicadas por la bibliografía dicha actividad no está explícitamente representada en el arte rupestre con una frecuencia equivalente a su importancia social.

En relación al primer grupo de criterios analíticos especificado en este trabajo, referente a los personajes que forman la escena, podemos hacer varias observaciones derivadas del análisis detallado de las imágenes que clasificamos como de bailes. En ese sentido, es interesante señalar que, a pesar de que todos los individuos exhiben posturas dinámicas, este dinamismo se presenta en mayor grado en la escena de danza individual del Abrigo del Tío Garroso, en la cual el movimiento se expresa en todas 


\begin{tabular}{|c|c|c|c|c|c|c|c|}
\hline \multirow[b]{2}{*}{$\begin{array}{l}\text { NOMBRE } \\
\text { DEL SITIO }\end{array}$} & \multicolumn{2}{|c|}{ Personaje } & \multicolumn{4}{|c|}{ DANZA } & \multirow[b]{2}{*}{$\begin{array}{l}\text { Período } \\
\text { CRONO- } \\
\text { ESTILÍstico }\end{array}$} \\
\hline & $\begin{array}{l}\text { POSTURA } \\
\text { CORPORAL }\end{array}$ & $\begin{array}{c}\text { OBJETOS Y } \\
\text { ORNAMENTACIÓN }\end{array}$ & $\begin{array}{l}\text { TIPO DE } \\
\text { DANZA }\end{array}$ & \begin{tabular}{|c|} 
GÉNERO \\
DE LOS \\
PERSONAJES
\end{tabular} & $\begin{array}{l}\text { TIPO DE INTERACCIÓN } \\
\text { ENTRE LOS PERSONAJES }\end{array}$ & $\begin{array}{l}\text { DIRECCIÓN DEL } \\
\text { MOVIMIENTO }\end{array}$ & \\
\hline $\begin{array}{l}\text { Abrigo del Tío } \\
\text { Garroso } \\
\text { (Teruel) }\end{array}$ & $\begin{array}{l}\text { tronco } \\
\text { curvado, } \\
\text { brazos } \\
\text { levantados } \\
\text { y piernas } \\
\text { flexionadas }\end{array}$ & $\begin{array}{l}\text { tocado, adornos en } \\
\text { las rodillas y arco }\end{array}$ & individual & masculino & - & $\begin{array}{l}\text { vertical, sin } \\
\text { desplazamiento } \\
\text { horizontal }\end{array}$ & estilizado \\
\hline $\begin{array}{l}\text { Cingle de la } \\
\text { Mola Remígia } \\
\text { (Castellón) }\end{array}$ & $\begin{array}{l}\text { tronco } \\
\text { inclinado y } \\
\text { ligeramente } \\
\text { curvado }\end{array}$ & $\begin{array}{c}\text { máscara de } \\
\text { toro, tocado de } \\
\text { cervatillo, adornos } \\
\text { en forma de cola } \\
\text { de animal, arcos y } \\
\text { flecha }\end{array}$ & pareja & masculino & $\begin{array}{l}\text { estrecha con contacto } \\
\text { entre las figuras } \\
\text { e indicación de } \\
\text { sincronía }\end{array}$ & $\begin{array}{l}\text { vertical, sin } \\
\text { desplazamiento } \\
\text { horizontal }\end{array}$ & linear \\
\hline $\begin{array}{l}\text { Cova Remígia } \\
\text { (Castellón) }\end{array}$ & $\begin{array}{c}\text { tronco } \\
\text { inclinado, } \\
\text { brazos abiertos } \\
\text { y levantados }\end{array}$ & $\begin{array}{c}\text { ¿máscaras?, adornos } \\
\text { en forma de cola } \\
\text { de animal, arcos y } \\
\text { flechas }\end{array}$ & pareja & masculino & $\begin{array}{l}\text { estrecha con contacto } \\
\text { entre las figuras } \\
\text { e indicación de } \\
\text { sincronía }\end{array}$ & $\begin{array}{l}\text { vertical, sin } \\
\text { desplazamiento } \\
\text { horizontal }\end{array}$ & linear \\
\hline $\begin{array}{l}\text { Abrigo } \\
\text { de los } \\
\text { Trepadores } \\
\text { (Teruel) }\end{array}$ & $\begin{array}{l}\text { tronco } \\
\text { inclinado, } \\
\text { brazos } \\
\text { levantados } \\
\text { y piernas } \\
\text { abiertas }\end{array}$ & $\operatorname{arcos}$ & $\begin{array}{l}\text { colectiva } \\
\text { lineal }\end{array}$ & masculino & $\begin{array}{l}\text { estrecha con contacto } \\
\text { entre las figuras } \\
\text { e indicación de } \\
\text { sincronía }\end{array}$ & $\begin{array}{l}\text { vertical, sin } \\
\text { desplazamiento } \\
\text { horizontal }\end{array}$ & filiforme \\
\hline $\begin{array}{l}\text { Cova Remígia } \\
\text { (Castellón) }\end{array}$ & $\begin{array}{l}\text { tronco } \\
\text { ligeramente } \\
\text { inclinado } \\
\text { y brazos } \\
\text { levantados }\end{array}$ & $\begin{array}{c}\text { adorno en forma } \\
\text { de cola de animal } \\
\text { y arcos }\end{array}$ & $\begin{array}{l}\text { colectiva } \\
\text { lineal }\end{array}$ & masculino & $\begin{array}{l}\text { estrecha con contacto } \\
\text { entre las figuras } \\
\text { e indicación de } \\
\text { sincronía }\end{array}$ & $\begin{array}{l}\text { vertical, sin } \\
\text { desplazamiento } \\
\text { horizontal }\end{array}$ & filiforme \\
\hline
\end{tabular}

FIG. 6. Esquema de las caracteristicas relativas a los personajes, tipos de danza y periodo cronoestilístico de las escenas clasificadas como representaciones de bailes.

las partes del cuerpo del bailarín. Por otro lado, en las escenas de danza en pareja o colectiva, pintadas en el Abrigo de los Trepadores, en el Cingle de la Mola Remígia y en Cova Remígia, el movimiento de las figuras tiende a concentrarse en la parte superior del cuerpo, mostrándose a través de la curvatura o inclinación del tronco y mediante la realización de movimientos coordinados con los brazos. Además, llama la atención el hecho de que en las dos escenas de danza colectiva identificadas - una de ellas ubicada en Teruel y la otra en Castellón- los personajes presenten una postura corporal similar, con brazos levantados y ostentando arcos ante una posible figura humana sacrificada. En ese sentido, cabe destacar también la notable similitud estructural en el posicionamiento de los bailarines antropozoomorfos de Cova Remígia y del Cingle de la
Mola Remígia, dos conjuntos situados uno al lado del otro en el Barranco de la Gasulla. Con respecto al uso de ornamentación, se observa la representación de tocados, máscaras, adornos en las rodillas y adornos en forma de cola de animal, mientras que los objetos utilizados por los individuos son arcos y flechas empleados de forma ajena a su función original. Obviamente, en el arte levantino los objetos y elementos de ornamentación no son exclusivos de las escenas de danza, pero su empleo en tal contexto refuerza el carácter simbólico de la actividad realizada.

Examinando el segundo grupo de criterios analíticos, centrado en la representación de la danza, como ya se ha podido observar a lo largo de este artículo hemos encontrado ejemplos de los tres tipos de bailes según el número de figuras: individuales, 
en pareja y colectivos. Sin embargo, en lo que se refiere a estos últimos, solo hemos identificado la realización de danzas lineales, contrastando con el predominio de las danzas circulares del otro extremo del Mediterráneo (Garfinkel, 1998: 220; 2003: 44-47). Sobre el género de los antropomorfos involucrados en el baile, observamos que en todos los casos donde hemos certificado su caracterización como danzantes los individuos involucrados en esta actividad son, sin excepción, masculinos. Esto contrastaría con ciertas escenas encontradas en conjuntos levantinos de la región de Murcia -como el Barranco de los Grajos I (Mateo, 2003) o el abrigo de La Risca I (García del Toro, 1986-87)- donde sí que se encuentran danzas protagonizadas por mujeres. Es cierto, sin embargo, que si la escena de Cova de Rossegadors se confirmara con un baile, tendríamos al menos una danza femenina pintada en el área de estudio, con lo cual habría que esperar antes de afirmar que este concepto es significativo. En cuanto a la interacción entre los bailarines y la dirección de los movimientos de la danza, encontramos que en las cinco escenas clasificadas como danzas los personajes exhiben una interacción muy estrecha, habiendo contacto entre los mismos mientras parecen danzar ejecutando movimientos sincronizados en el mismo lugar, es decir, sin la realización de desplazamientos horizontales en el espacio.

La caracterización de estas escenas nos lleva inevitablemente a reflexionar sobre la posible función de las mismas en la sociedad levantina. Teniendo en cuenta que el arte rupestre es un sistema de comunicación que, a través de la representación de imágenes, permite la transmisión de informaciones específicas a los observadores que conocen las normas del código gráfico, podemos hipotetizar que estas pinturas funcionarían esencialmente como un dispositivo mnemotécnico, utilizado para informar no solo sobre la danza en sí, sino también sobre todo el contexto cultural en el que se desarrolló dicha actividad. No obstante, conviene recordar que la danza es una actividad elaborada a partir de símbolos culturalmente entendidos en contextos específicos (Kaeppler, 1992), por lo que en el momento presente de la investigación consideramos

Ediciones Universidad de Salamanca / ®@ excesivamente arriesgado clasificar categóricamente estas escenas como bailes fálicos, agrícolas, de culto a divinidades, etc.

Finalmente, desde un punto de vista cronológico, los criterios cronoestilísticos establecidos tanto hace décadas (Obermaier y Wernert, 1919: 94-96) como en los últimos años (Domingo, 2006, 2012; Utrilla y Bea, 2007; Utrilla et al., 2012) establecen para el arte levantino una periodización con, al menos, un primer momento de figuras humanas de tipo naturalista, con piernas gruesas y tronco corto -denominadas Paquípodos, Horizonte Centelles o Arquetipo Robusto, según el autor que lo defina); un segundo momento con individuos de piernas menos gruesas y tronco más proporcionado o alargado -denominados Cestosomáticos, Horizonte Civil o Arquetipo Estilizado-; una tercera fase con motivos humanos de estructura estilizada y elaborados con trazos sencillos -conocidos como Tipo Linear, Horizonte Linear o Nematomorfos-; y un último período con figuras de construcción minimalista elaboradas a partir de trazos bastante finos -mencionados en la bibliografía como Tipo Filiforme e equivalentes, para ciertos autores, al Horizonte Linear y al Tipo Nematomorfo-.

Analizando las escenas que consideramos como representaciones de danzas según los criterios aquí especificados, observamos que el bailarín solitario del Tío Garroso presenta características tecnomorfológicas correspondientes al segundo período cronoestilístico, el estilizado. Por otro lado, las parejas de Cova Remígia y del Cingle de la Mola Remígia exhiben rasgos típicos del llamado Horizonte Linear, mientras que las dos danzas colectivas encontradas en el Abrigo de los Trepadores y en Cova Remígia se pueden atribuir al período filiforme. De este modo, a pesar de las excepción identificada en el Abrigo del Tío Garroso, las evidencias parecen indicar que las escenas de danza se pintaron predominantemente en las últimas etapas del arte levantino encontrado en el área de estudio. Esta conclusión, en cierta forma, entra en contradicción con la perspectiva clásica de que la tradición rupestre levantina evoluciona de temas estrictamente sociales a temas cinegéticos. 


\section{Conclusión}

El análisis de las trece escenas citadas como representaciones de danza en la bibliografía sobre arte levantino del Bajo Aragón y del Maestrazgo ha tenido como fin comprobar si las mismas presentan los atributos necesarios para dicha clasificación. Como resultado de esta revisión hemos concluido que solamente cinco escenas presentan características que se ajustan claramente a los parámetros típicos de representaciones de danza, entre las cuales se pueden distinguir bailes individuales, en parejas y colectivos de tipo lineal. Los yacimientos donde se localizan estas representaciones se encuentran en las dos grandes zonas del área de estudio, cada región con dos sitios que geográficamente se sitúan muy cercanos: Trepadores y Tío Garroso en el territorio aragonés, ambos en Alacón, y Cingle de la Mola Remígia y Cova Remígia en el área de Castellón, ambos en Ares del Maestrat. En ese contexto, a pesar de su baja representatividad desde el punto de vista cuantitativo, las escenas de danza pintadas en los abrigos del Bajo Aragón y del Maestrazgo son una fuente crucial de información para la comprensión del proceso de desarrollo del arte levantino y de las prácticas culturales realizadas en la Prehistoria de la Península Ibérica.

\section{Bibliografía}

Almagro, M. (1946): "Arte Prehistórico". En Almagro, M. y García y Bellido, A. (eds.): Ars Hispaniae. Historia Universal del Arte Hispánico. Madrid: Plus Ultra, pp. 13-133.

Almagro, M. (1960): "Nuevas pinturas rupestres con una danza fálica en Albarracín". En Freund, G. (ed.): Festschrift für Lothar Zotz. Steinzeitfragen der alten und neuen Welt. Bonn: Ludwing Röhrscheid Verlag, pp. 457-465.

Alonso, A. y Grimal, A. (2001): "Arte levantino en Castellón”, Millars: Espai i Historia, 24, pp. 111-152.

BEA, M. (2006-08): "Aproximación al estudio de la perspectiva en el arte levantino", Bolskan, 23, pp. 127134.

Ediciones Universidad de Salamanca / 묭
BeA, M. (2018): "Catálogo de yacimientos: pinturas". En Rodanés, J. M. (ed.): Arte Rupestre en Aragón. Zaragoza: Gob. de Aragón, pp. 103-361.

BEA, M. (2020): "When not everything is as nice as its looks. Social veiled conflicts in Levantine rock art (Spain)", Quaternary International, 544, pp. 12-22.

Beltrán, A. (1968): "El arte rupestre levantino: Cronología y significación”, Caesaraugusta, 31-32, pp. 7-44.

Beltrán, A. (1985): "Problemas del Arte Rupestre Levantino en la Provincia de Castellón", Cuadernos de Prehistoria y Arqueología Castellonenses, 11, pp. 111140.

Beltrán, A. (1998): "Sacralización de lugares y figuras en el arte rupestre levantino del río Martín (Albalate del Arzobispo y Alcaine, Teruel)", Quaderns de Prehistòria i Arqueología de Castelló, 19, pp. 43-52.

Beltrán, A. y Royo, J. (2005): Las pinturas rupestres del Cerro Felió, Alacón (Teruel). Alacón: Ayuntamiento de Alacón.

Breuil, H. (1908): "Les pintures quaternaries de la Roca del Cogul”, Butlletí del Centre Escursionista de Lleyda, 1, pp. 10-13.

Breuil, H. y Cabré, J. (1909): "Les peintures rupestres du Bassin Inferieur de l'Ebre. I. les roches peintes de Calapatá à Cretas (Bas Aragon). II. Les fresques à l'air libre de Cogul, province de Lérida (Catalogne)", L'Anthropologie, 20, pp. 1-21.

Bundo, D. (2001): "Social relationship embodied in singing and dancing performances among the Baka", African Study Monographs, 26, pp. 85-101.

CABRÉ, J. (1925): "Las pinturas rupestres de la Valltorta. Escena bélica de la Cova de Cevil", Memorias de la Sociedad Española de Antropología, Etnografia y Prehistoria, 4, pp. 201-233.

Domingo, I. (2006): "La figura humana: paradigma de continuidad y cambio en el arte rupestre levantino", Archivo de Prehistoria Levantina, 26, pp. 161-192.

Domingo, I. (2012): "Figura humana, técnicas y territorios: hacia una redefinición técnica del arte rupestre levantino-Human figures, techniques and territories: towards a technical redefinition of Levantine rock art". En Garcí́a, J.; Collado, H. y Nash, G. (eds.): La cuestión levantina-The Levantine question. Budapest-Cáceres: Archaeolingua, pp. 117-144.

Domingo, I.; López-Montalvo, E.; Villaverde, V. y Martínez Valle, R. (2007): Los Abrigos VII, VIII y IX de Les Coves de Ia Saltadora. Les Coves de Vinromà, Castelló. Valencia: Generalitat Valenciana. 
EscorizA, T. (2002): "Representations of Women in Spanish Levantine Rock Art: An Intentional Fragmentation", Journal of Social Archaeology, 2, pp. 81108.

FELD, S. (1982): Sounds and sentiment: birds, weeping, poetics, and song in Kaluli expression. Durham-London: DUP.

García del Toro, J. R. (1986-87): "La danza femenina de la Risca (Moratalla, Murcia)”, Bajo Aragón Prehistoria, 7-8, pp. 123-127.

Garfinkel, Y. (1998): "Dancing and the Beginning of Art Scenes in the Early Village Communities of the Near East and Southeast Europe", Cambridge Archaeological Journal, 8 (2), pp. 207-237.

Garfinkel, Y. (2003): Dancing at the Dawn of Agriculture. Austin: UTP.

Garfinkel, Y. (2010): "Dance in Prehistoric Europe", Documenta Praehistorica, 37, pp. 205-214.

Hanna, J. L. (1987): "Dance and Religion". En EliaDE, M. (ed.): The Encyclopedia of Religion. New York: Macmillan Publishing Company, pp. 203-212.

Hernández Pacheco, E. (1917): "Estudios de arte prehistórico. I. Prospección de las pinturas rupestres de Morella la Vella. II. Evolución de las ideas madres de las pinturas rupestres", Revista de la Real Academia de Ciencias Exactas, Físicas y Naturales de Madrid, 16, pp. 62-84.

JordÁ, F. (1970-71): "Los Tocados de Plumas en el Arte Rupestre Levantino", Zephyrus, xxI-XXII, pp. 35-72.

JoRDÁ, F. (1974): "Las representaciones de danzas en el arte rupestre levantino". En III Congreso Nacional de Arqueología. Porto: Junta Nacional de Educação, pp. 43-52.

JoRDÁn, J. F. (2006): "Narraciones de mitos entre los cazadores postpaleolíticos de la Península Ibérica: cuerpos estilizados, escalas con miel, animales en trance de muertey la Hija del Señor del Bosque", Cuadernos de Arte Rupestre, 3, pp. 79-124.

Kaeppler, A. L. (1992): “Dance”. En Bauman, R. (ed.): Folklore, cultural performances, and popular entertainments. A Communications-centered Handbook. New York: oup, pp. 196-203.

Katz, R. (1982): Boiling Energy: Community Healing among the Kalahari !Kung. Cambridge: HAuP.

Lewis-Williams, J. D. (1999): "Dance and Representation”, Cambridge Archaeological Journal, 9 (2), pp. 281-283.

Lewis-Williams, J. D. y Challis, S. (2011): Deciphering Ancient Minds. London: Thames and Hudson.
López-Montalvo, E. (2007): Análisis interno del Arte Levantino: la composición y el espacio a partir de la sistematización del núcleo Valltorta-Gassulla. Valencia: Univ. de Valencia.

López-Montalvo, E. (2018): "Hunting scenes in Spanish Levantine rock art: an unequivocal chrono-cultural marker of Epipaleolithic and Mesolithic Iberian societies?", Quaternary International, 472, pp. 205220.

Marshall, L. (1969): "The Medicine Dance of the Kung Bushmen”, Africa, 39, pp. 347-381.

Mateo, M. Á. (1995-96): "La vida cotidiana en el arte rupestre levantino", Anales de Prehistoria y Arqueologia, 11-12, pp. 79-90.

Mateo, M. Á. (2003): "Religiosidad prehistórica. Reflexiones sobre la significación del arte rupestre levantino", Zephyrus, LVI, pp. 247-268.

Mesado, N.; Barreda, J.; Rufino, A. y Viciano, J. L. (2008): "Tres nuevas manifestaciones de arte rupestre prehistórico en la provincia de Castellón”, Archivo de Prehistoria Levantina, 27, pp. 181-224.

Mguni, S. (2015): Termites of the gods: San cosmology in Southern African rock art. Johannesburgo: Wits University Press.

Molinos, M. I. (1986-87): "Representaciones de carácter bélico en el arte rupestre levantino", Bajo Aragón, Prehistoria, 7-8, pp. 295-310.

Obermaier, H. y Wernert, P. (1919): Las pinturas rupestres del Barranco de la Valltorta (Castellón). Madrid: Comisión de Investigaciones Paleontológicas y Prehistóricas.

Olaria, C. (2011): Del sexo invisible al sexo visible. Las imágenes femeninas postpaleoliticas del Mediterráneo peninsular. Castellón: Servei d'Investigacions Arqueòlogiques i Prehistòriques.

Ortego, T. (1948): "Nuevas estaciones con arte rupestre aragonés: El Mortero y el Cerro Felío en el término de Alacón (Teruel)", Archivo Español de Arqueología, 21, pp. 3-37.

Picazo, J. V.; Loscos, R. M.; Bea, M. y Perales, M. P. (2001-2002): "Las pinturas rupestres de la Cueva del Chopo (Obón, Teruel)”, Kalathos, 20-21, pp. 27-83.

Picazo, J. V. y Martínez Bea, M. (2005): "Bumeranes y armas arrojadizas en el Arte Rupestre levantino. Las aportaciones de la Cueva del Chopo (Obón, Teruel)". En Hernández Pérez, M. S. y Soler Díaz, J. A. (eds.): Arte rupestre en la España mediterránea. Actas Congreso celebrado en Alicante, 2004. Alicante: Instituto Juan Gil-Albert, pp. 283-295. 
Porcar, J. B. (1945a): "Iconografía rupestre de la Gasulla y Valltorta. Danza de arqueros entre figuras humanas sacrificadas", Boletín de la Sociedad Castellonense de Cultura, 21, pp. 145-178.

Porcar, J. B. (1945b): "Interpretaciones sobre el arte rupestre", Archivo de Prehistoria Levantina, 2, pp. 31-37.

Ripoll, E. (1961): Los abrigos pintados de los alrededores de Santolea (Teruel). Barcelona-New York: Instituto de Prehistoria y Arqueología de la Diput. de Barcelona-Wenner Gren Foundation for Anthropological Research.

Ripoll, E. (1963): Pinturas rupestres de la Gasulla (Castellón). Barcelona: Diput. de Barcelona.

Ripoll, E. (1990): "Acerca de algunos problemas del arte rupestre postpaleolítico en la Península Ibérica”, Espacio, Tiempo y Forma, 3, pp. 71-104.

Rossano, M. (2020): Ritual in human evolution and religion: psychological and ritual resources. New York: Routledge.

Rubio, A.; Viñas, R. y Santos da Rosa, N. (2019): "Representacions bèl-liques de l'art llevantî". En VINAS, R. (ed.): I Jornades Internacionals d'Art Rupestre de l'Arc Mediterrani de la Peninsula Ibèrica. Xxè Aniversari de la Declaració de Patrimoni Mundial (Montblanc, 2019). Montblanc: Centre d'Interpretació de l'Art Rupestre de les Muntanyes de Prades, pp. 227244.

Ruiz, J. F. y Royo, J. (2017): Guía Cañada de Marco. Alcaine: Ayto. de Alcaine.

SARRIÀ, E. (1988-89): "Las pinturas rupestres de Cova Remigia (Ares del Maestre, Castellón)", Lucentum, 7-8, pp. 7-33.

SeEger, A. (2003): "Music and Dance". En Ingold, T. (ed.): Companion Encyclopedia of Anthropology. Londres: Routledge, pp. 686-705.
Utrilla, P.; Baldellou, V. y Bea, M. (2012): “Arte Levantino y territorio: el modelo aragonés-Aragon and Spanish Levantine: a territorial study". En GARcía, J.; Collado, H. y Nash, G. (eds.): La cuestión levantina-The Levantine question. Budapest-Cáceres: Archaeolingua, pp. 262-282.

Utrilla, P. y Bea, M. (2006): "Arte levantino y territorio en la España mediterránea”, Clio, 20, pp. 17-52.

Utrilla, P. y Bea, M. (2007): "La figura humana en el arte levantino aragonés", Cuadernos de Arte Rupestre, 4, pp. 163-205.

Utrilla, P. y Bea Martínez, M. (2016): "Ritual y simbolismo en el Barranco del Pajarejo". En Aguilera, I.; Beltrán, F.; Dueñas, M. J.; Lomba, C. y Paz, J. A. (eds.): De las ánforas al museo. Estudios dedicados a Miguel Beltrán Lloris. Zaragoza: IFC, pp. 803-816.

Vilaseca, S. (1947): Las pinturas rupestres de la Cueva del Polvorín (Puebla de Benifazá, provincia de Castellón). Madrid: Comisaría Gral. de Excavaciones Arqueológicas.

VIÑAS, R. (1982): La Valltorta. Arte rupestre del levante español. Barcelona: Edic. Castell.

Viñas, R. y MartíneZ, R. (2001): "Imágenes antropo-zoomorfas del Postpaleolítico castellonense", Quaderns de Prehistòria i Arqueologia de Castelló, 22, pp. 365-392.

Viñas, R.; Morote, J. G. y Rubio, A. (2015): El Proyecto: Arte Rupestre del Parque Valltorta-Gasulla y zona norte de Castellón. Castellón: Diput. de Castellón

Whitley, D. S. (2011): "Rock Art, religion, and ritual". En Insoll, T. (ed.): The Oxford Handbook of the Archaeology of Ritual and Religion. Oxford: oup, pp. 307-327.

Winkelman, M. J. (2017): "Shamanism and the Brain". En Clements, N. K. (ed.): Religion: mental religion. New York: Macmillan, pp. 355-372.Ibus. Sedit 